\title{
ICD-11 chapter on mental and behavioural disorders: heralding new ways of seeing old problems
}

\author{
O. Gureje \\ Professor and Director, WHO Collaborating Centre for Research and Training in Mental Health, Neurosciences and Drug and Alcohol Abuse, \\ Department of Psychiatry, University of Ibadan, Nigeria
}

Key words: Behaviour problems, ICD 10, psychoactive substance use disorder, schizophrenia.

The process of revising the 10th edition of the International Classification of Diseases and Related Health Problems (ICD-10) by the World Health Organization (WHO) is currently in its final stages with the 11th edition (ICD-11) scheduled for presentation to the World Health Assembly for approval in 2018. By this activity, the WHO will be fulfilling its responsibility 'to establish and revise as necessary international nomenclatures of diseases, of causes of death and of public health practices' and 'to standardize diagnostic procedures as necessary' (World Health Organization, 2009). The revision of the Chapter on Mental and Behavioural Disorders by the WHO Department of Mental Health and Substance Abuse is a part of this process.

The significance of revising the classification of mental and behavioural disorders is better appreciated within the context of the large unmet need that exists globally for these disorders (Gureje \& Reed, 2012). Even though mental disorders account for a higher percentage of global disease burden than any other category of non-communicable disease, as many as $50 \%$ of persons with serious mental disorders in highincome countries and over $75 \%$ of those in low- and middle-income countries do not receive any care (Wang, Aguilar-Gaxiola et al. 2007). The major reason for this huge treatment gap is lack of access to appropriate service by persons with these disorders. Nevertheless, there is also a clear need for a reliable way to describe and communicate the conditions that may require clinical care. That is, a classification of the conditions that define eligibility for services that is valid and useful at the point at which such persons are most likely to come into contact with the health care system will facilitate the provision of appropriate

Address for correspondence: O. Gureje, Professor and Director, WHO Collaborating Centre for Research and Training in Mental Health, Neurosciences and Drug and Alcohol Abuse, Department of Psychiatry, University of Ibadan, Nigeria

(Email: ogureje@comui.edu.ng) interventions. The current ICD-10 was approved by the World Health Assembly in 1990. Substantial scientific evidence has accumulated since that time that has direct relevance to the validity of disorder categories, their boundaries with normality as well as with each other. A revised classification should facilitate the use of this evidence to inform improved service delivery.

At the outset of the revision activities, the International Advisory Group for the Revision of the ICD-10 Mental and Behavioral Disorders decided that improving clinical utility would be a major orienting principle of the process (International Advisory Group for the Revision of ICD-10 Mental \& Behavioural Disorders, 2011). Although previous versions of the ICD have typically emphasised clinical utility as their highest priority, relatively little attention has been paid to this in practice (First, Pincus et al. 2004; First, 2010; First, Bhat et al. 2014) Clinical utility is critical in improving user-friendliness, contextual goodness of fit and the promotion of efficient clinical information across different levels of the health system with the ultimate goal of enhancing good clinical practice. According to the WHO: 'the clinical utility of a classification construct or category for mental and behavioral disorders depends on: (a) its value in communicating (e.g., among practitioners, patients, families, administrators); (b) its implementation characteristics in clinical practice, including its goodness of fit (i.e., accuracy of description), its ease of use, and the time required to use it (i.e., feasibility); and (c) its usefulness in selecting interventions and in making clinical management decisions'(Reed, 2010).

The revision process is being guided by a program of cutting-edge research studies which are clearly innovative and pioneering in their conception and implementation (Keeley et al. 2016). The important steps in this program of work bear a brief description (Keeley et al. 2016). Following the conduct of an assessment of the perspectives and use of classification among key mental health professionals, principally psychiatrists and psychologists, and the analyses of 
existing country-level and regional adaptations of the ICD-10, two international 'formative' field studies were implemented. These studies examined clinicians' conceptualisations of the interrelationships among mental disorders categories and were designed to inform the development of the overarching architecture of the ICD-11. Subsequently, the WHO developed the Global Clinical Practice Network (www.globalclinicalpractice.net), a platform through which more than 13000 health professionals from 151 countries indicated their agreement to participate in a series of internet-based field studies for ICD-11. These internetbased field studies have provided a unique opportunity for applying experimental methods to compare the application of the new ICD-11 disorder descriptions and guidelines with those of ICD-10 in order to assess relative improvements in their conceptualisations and potential impact on clinical utility. The final piece in the list of activities to provide an empirical basis for the new ICD is the implementation of clinic-based field studies. These studies are being conducted in a range of research centres spread across the world and are designed to test the reliability and clinical utility of the proposed classification in real-life clinical settings. The overall approach to revising the ICD and producing the 11th edition has therefore been implemented with a determined effort to generate international participation and inclusive decision-making (Gureje \& Stein, 2012).

The two editorials featured in this issue of the Journal exemplify the products of the rigour that has gone into the revision exercise and show in bold relief the importance of focusing attention on the clinical utility of the new classification (Keeley and Gaebel In press; Poznyak et al. In press). The introduction of symptom rating scales for schizophrenia and other primary psychotic disorders represents a major change in the way these disorders are described and classified (Keeley and Gaebel In press). The development is a bold attempt to respond to the well-known inadequacies of the previous subtype system, including the instability of the subtypes as well as the observation that many patients with schizophrenia do not fit neatly into any of the subtypes. The proposed six domains in ICD-11 provide a new way of capturing the diverse clinical features of patients with psychosis and should lead to the improved ability of clinicians to respond appropriately to areas of clear needs for intervention. For example, a co-occurring mood component would henceforth receive the attention it needs because the rating profile will clearly provide an indication of its presence and severity.

Equally important are the new changes made to the disorders due to substance use in ICD-11(Poznyak et al. In press.). The field of substance use is one of continual movement both in regard to the frequent emergence of new substances, changes in the routes of their administration, as well as the changing pattern of the consequences of use. In addition, international drug policies are also changing either in response to better scientific knowledge or to shifting public opinion. Prevention and treatment approaches that have the potential for effectiveness need a classificatory system that takes due cognizance of these changes. For example, the introduction of the greater specification of different harmful patterns of substance abuse, ranging from episodic, recurrent, to continuous, in the ICD-11 has important implications for the specificity of prevention and treatment approaches. Also, by simplifying the diagnostic guidelines for substance dependence, the new classification will improve the clinical utility of the category especially in non-specialist settings where the great majority of new cases are likely to make their first encounter with the health system.

Improved clinical utility is the major goal of the revision process for the ICD-11 Chapter on Mental and Behavioural Disorders. The changes that have been made across the groups of these disorders, some examples of which are highlighted in the two editorials in this issue, seem to have been designed to achieve this goal. The extent to which this is actually the case will be shown by how much the new classification helps to bridge the treatment gap that currently exists for mental disorders across the world, but more so in low- and middle-income countries.

\section{Acknowledgement}

Oye Gureje is a member of the International Advisory Group for the Revision of ICD-10 Chapter on Mental and Behavioural Disorders, the Chair of the Somatic Distress and Dissociative Disorders Work Group and the Vice Chair of the Field Studies Coordinating Group. The author acknowledges the discussions within these groups that have shaped the views expressed in this piece but takes responsibility for these views.

\section{References}

First M, Pincus H, Levine J, Williams J, Ustun B, Peele R (2004). Clinical utility as a criterion for revising psychiatric diagnoses. American Journal of Psychiatry 161(6), 946-954.

First MB (2010). Clinical utility in the revision of the diagnostic and statistical manual of mental disorders (DSM). Professional Psychology Research and Practice 41(6), 465-473.

First MB, Bhat V, Adler D, Dixon L, Goldman B, Koh S, Levine B, Oslin DW, Siris SG (2014). How do clinicians actually use the DSM in clinical practice and why we need 
to know more. Journal of Nervous and Mental Disease 202(12), 841-844.

Gureje O, Reed G (2012). Revising the classifications of mental disorders: do we really need to bother? International Review of Psychiatry 24(6), 511-513.

Gureje O, Stein DJ (2012). Classification of mental disorders: the importance of inclusive decision-making. International Review of Psychiatry 24(6), 606-612.

International Advisory Group for the Revision of ICD-10 Mental and Behavioural Disorders (2011). A conceptual framework for the revision of the ICD-10 classification of mental and behavioural disorders. World Psychiatry 10, 86-93.

Keeley J, Gaebel W (In press). Symptom rating scales for schizophrenia and other primary psychotic disorders in ICD-11. Epidemiology and Psychiatric Sciences. doi: 10.1017/ S2045796017000270.

Keeley JW, Reed GM, Roberts MC, Evans SC, Medina-Mora ME, Robles R, Rebello T, Sharan P, Gureje O, First MB, Andrews HF, Ayuso-Mateos JL, Gaebel W, Zielasek J., Saxena S. (2016). Developing a science of clinical utility in diagnostic classification systems: field study strategies for ICD-11 mental and behavioural disorders. American Psychologist 71, 3-16.

Poznyak V, Reed GM, Medina-Mora ME (In press). Aligning the ICD-11 classification of disorders due to substance use with global service needs. Epidemiology and Psychiatric Sciences. doi: 10.1017/S2045796017000622.

Reed GM (2010). Toward ICD-11: improving the clinical utility of WHO's international classification of mental disorders. Professional Psychology Research and Practice 41, 457-464.

Wang PS, Aguilar-Gaxiola S, Alonso J, Angermeyer MC, Borges G, Bromet EJ, Bruffaerts R, de Girolamo G, de Graaf R, Gureje O, Haro JM, Karam EG, Kessler RC, Kovess V, Lane MC, Lees S, Levinson D, Ono Y, Petukhova M, Posada-Villa J, Seedat S, Wells JE (2007). Use of mental health services for anxiety, mood and substance disorders in 17 countries in the WHO world mental health surveys. Lancet 370(9590), 841-850.

World Health Organization (2009). Basic Documents, 47th edn. World Health Organization: Geneva, Switzerland. 